Supplement of Biogeosciences, 14, 341-351, 2017

http://www.biogeosciences.net/14/341/2017/

doi:10.5194/bg-14-341-2017-supplement

(C) Author(s) 2017. CC Attribution 3.0 License.

(c) (i)

Supplement of

\title{
Vertical profiles of sediment methanogenic potential and communities in two plateau freshwater lakes
}

Yuyin Yang et al.

Correspondence to: Shuguang Xie (xiesg@pku.edu.cn) and Yong Liu (yongliu@pku.edu.cn)

The copyright of individual parts of the supplement might differ from the CC-BY 3.0 licence. 
Figure S1 Methanogen community compositions based on 16S rRNA gene. Samples D1-D6 and E1-E6 were from Dianchi Lake and Erhai Lake, respectively. Samples D1-D6 and E1-E6 were retrieved from Dianchi Lake and Erhai Lake, respectively. Digits " $1 "$ " " 6 " were referred to sediment depth $0-5,5-8,8-11,11-14,14-17$ and 17-20 cm, respectively.

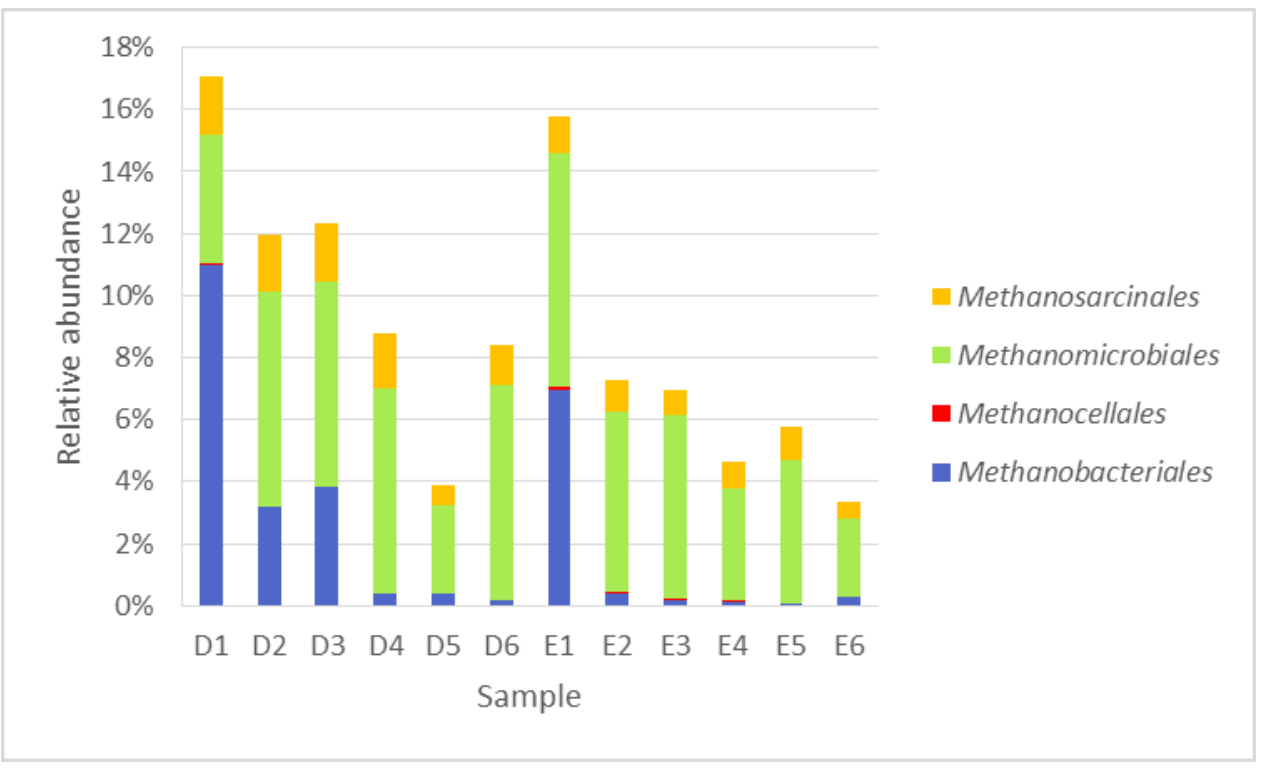


Figure S2 Methanogen community compositions based on $m c r A$ gene. Samples D1D6 and E1-E6 were from Dianchi Lake and Erhai Lake, respectively. Samples D1D6 and E1-E6 were retrieved from Dianchi Lake and Erhai Lake, respectively. Digits "1" - "6" were referred to sediment depth $0-5,5-8,8-11,11-14,14-17$ and 17-20 $\mathrm{cm}$, respectively.

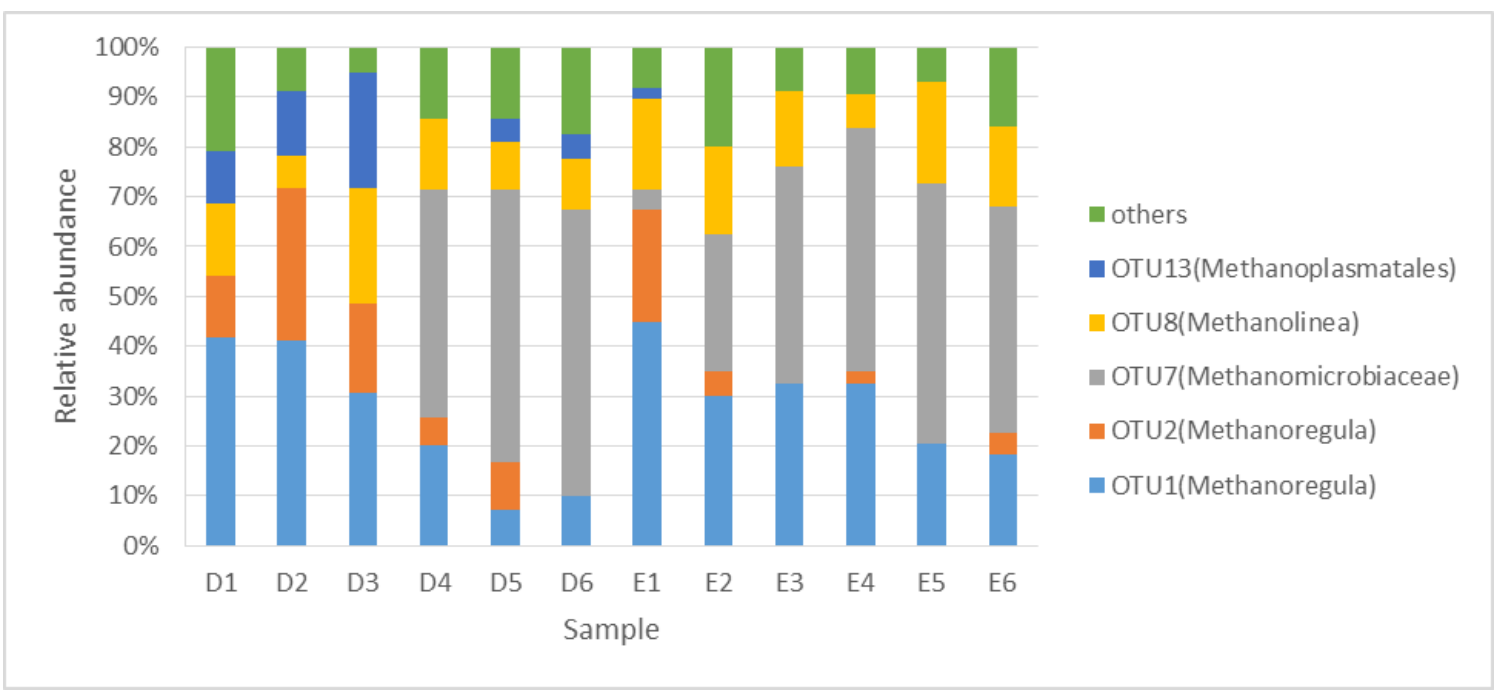


Figure S3 Physicochemical features of sediment samples from Dianchi Lake and

Erhai Lake

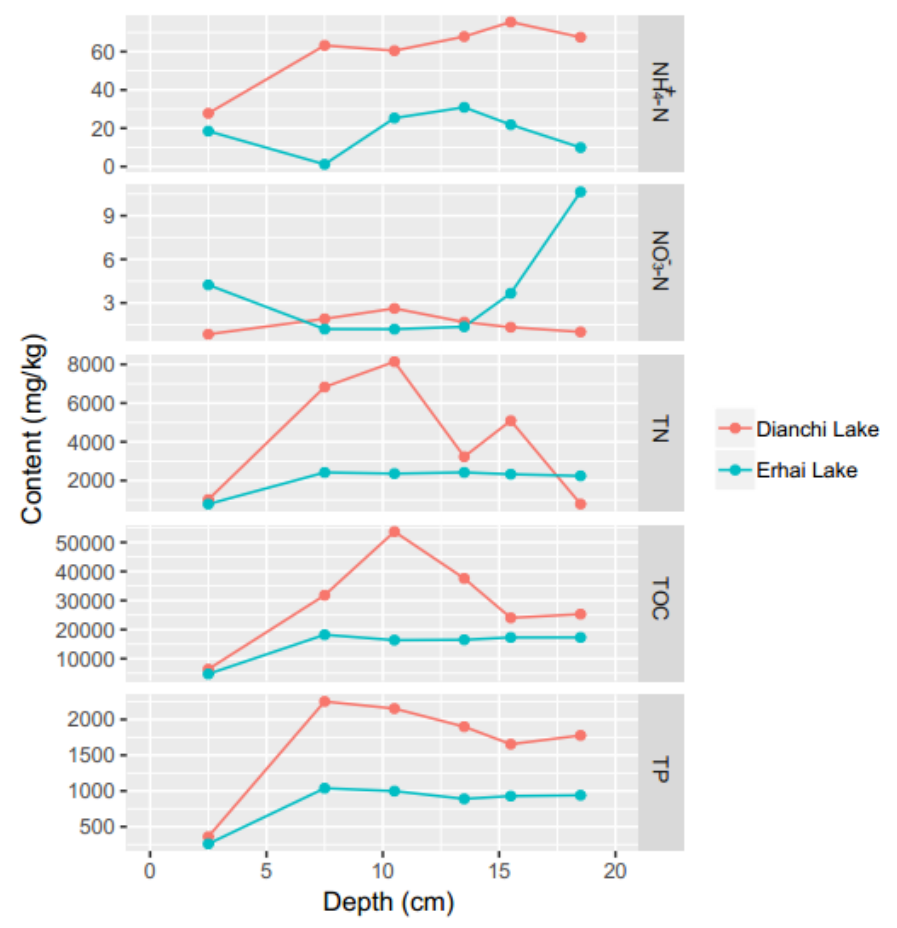

